Supporting Information

\title{
Stable Unassisted Solar Water Splitting on Semiconductor Photocathodes Protected by Multi-Functional GaN Nanostructures
}

\author{
Yongjie Wang ${ }^{1}$, Jonathan Schwartz ${ }^{2}$, Jiseok Gim², Robert Hovden², and Zetian $\mathrm{Mi}^{1{ }^{1 *}}$ \\ ${ }^{1}$ Department of Electrical Engineering and Computer Science, University of Michigan, \\ 1301 Beal Avenue, Ann Arbor, Michigan 48109, USA \\ ${ }^{2}$ Department of Materials Science and Engineering, University of Michigan, 2300 \\ Hayward Street, Ann Arbor, Michigan 48109, USA \\ *Corresponding author: ztmi@umich.edu
}




\section{Supplementary Experimental Section}

GaN/3J photocathode fabrication. Commercially available $\mathrm{GaInP}_{2} / \mathrm{GaAs} / \mathrm{Ge}$ triplejunction wafer (purchased from IQE Ltd.) was used in this study, with details shown in Table S2. GaN nanostructures were grown atop the wafer by plasma-assisted molecular beam epitaxy (MBE) under nitrogen-rich conditions to promote the formation of $\mathrm{N}$ terminated surfaces. Growth parameters used in this study include a substrate temperature $\sim 500{ }^{\circ} \mathrm{C}$, gallium (Ga) beam equivalent pressure (BEP) of 9E-8 Torr, germanium (Ge) cell temperature at $1050{ }^{\circ} \mathrm{C}$, nitrogen flow rate of $1 \mathrm{sccm}$, and nitrogen plasma power of 350 W. The growth duration was varied from 15 to 60 mins, which leads to GaN protection layers with different thicknesses, where 30 mins growth demonstrates the best performance.

Platinum nanoparticles deposition. Platinum (Pt) nanoparticles were deposited on textured GaN nanostructure surfaces as the cocatalyst nanoparticles for efficient proton reduction reaction by using an electroplating deposition method. Prepared in a threeelectrode configuration versus Pt counter electrode and Ag/AgCl reference electrode, the GaN/3J photocathode was kept at $\sim 0 \mathrm{~V}$ vs. RHE for 165 seconds in $1 \mathrm{mmol} \mathrm{H}_{2} \mathrm{PtCl}_{6}$ precursor solution under AM 1.5G one-sun illumination. The platinized GaN/3J photocathode was rinsed by pure water and then dried under argon ambient for subsequent photoelectrochemical measurements. Other deposition methods were also investigated, including photodeposition and electron-beam evaporation, but they did not show comparable results.

Photoelectrochemical measurements. Photoelectrochemical (PEC) measurements were conducted in both three-electrode and two-electrode configurations in $0.1 \mathrm{M} \mathrm{H}_{2} \mathrm{SO}_{4}$ electrolyte solution ( $\mathrm{pH}$ 1) equipped with a Newport solar simulator with AM 1.5G filter 
and one-sun intensity. The $\mathrm{Ag} / \mathrm{AgCl}$ reference electrode was only used for three electrode measurements. Gamry potentiostat device was used to perform all the PEC measurements including linear sweep voltammetry, chronoamperometry, and open circuit potential tests. $\mathrm{H}_{2}$ gas production from solar water splitting on GaN/3J photocathode was analyzed by injecting $1 \mathrm{~mL}$ gas sampling into a Shimazdu gas chromatograph machine (GC-8A). The active area of GaN/3J photocathode is in the range of $0.05 \sim 0.2 \mathrm{~cm}^{2}$. For long-term experiment in three-electrode configuration, the electrolyte was periodically refreshed to avoid accumulated heating effect.

Electron Microscopy. Scanning electron microscope (SEM) images were recorded with a secondary electron (SE) detector using a Hitachi SU8000 system (5 kV), Tescan MIRA3 system (15 kV), and a JEOL IT500 SEM (20 kV) with an EDX detector. HAADF-STEM images were collected using a JEOL 3100R05 microscope with double Cs aberration corrected STEM (300 keV, 22mrad) and simultaneous STEM EDS spectroscopic mapping obtained by JEOL EDX detector. Samples for STEM and EDS characterization were prepared using bladed exfoliation or in cross-section view by mechanical wedge polishing. 


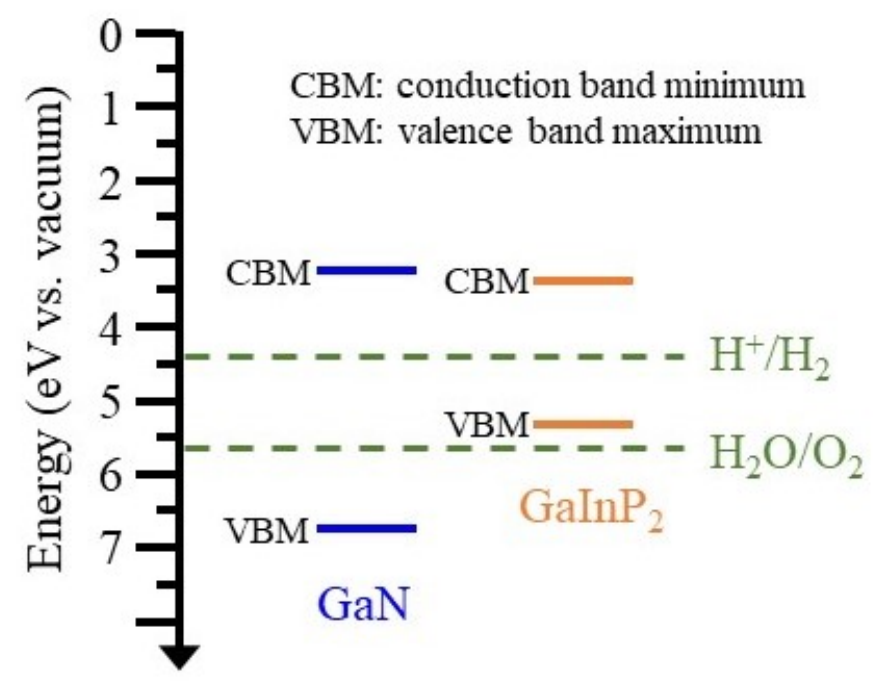

Supplementary Figure S1. Flat band diagram of $\mathrm{GaInP}_{2}$ and $\mathrm{GaN}$ semiconductors. Water redox potentials are listed as in $\mathrm{pH} \sim 1$ acidic electrolyte solutions. The small conduction band offset $(<0.2 \mathrm{eV})$ ensures smooth charge carrier transfer of photo-excited electrons from $\mathrm{GaInP}_{2}$ surface to $\mathrm{GaN}$ protection layer. ${ }^{1-3}$ 


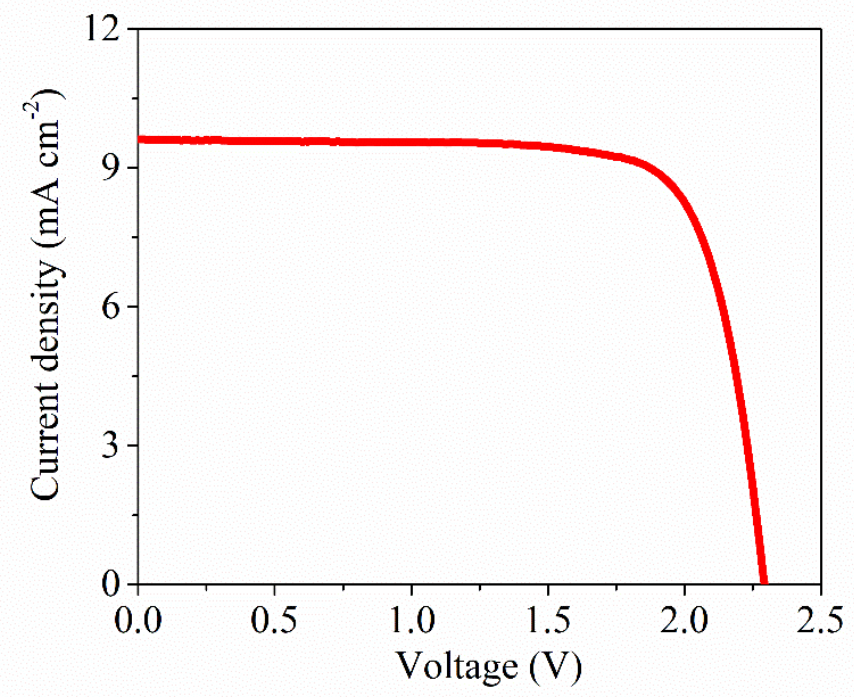

Supplementary Figure S2. Measured current-voltage characteristics of bare GaInP//GaAs/Ge triple junction photovoltaic device under AM 1.5G one sun illumination. 

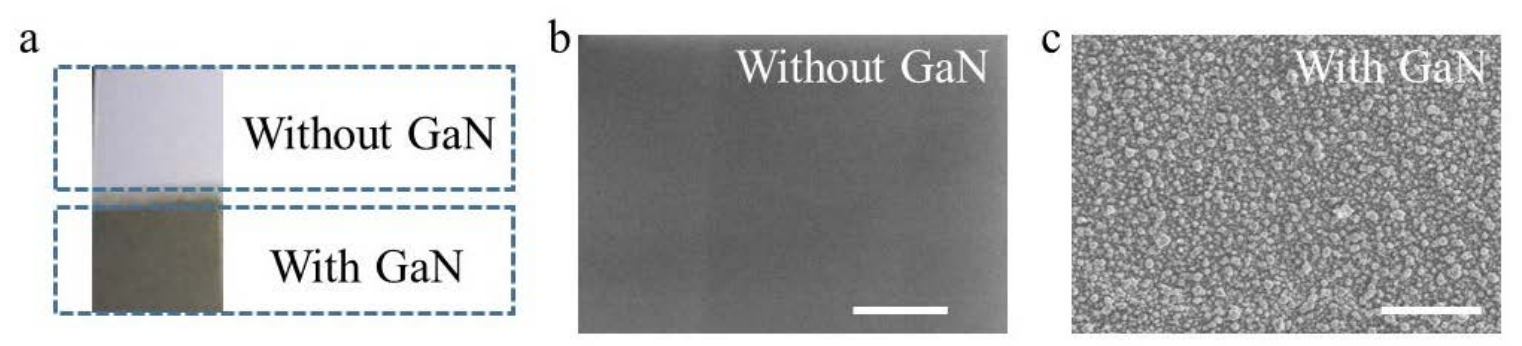

Supplementary Figure S3. Optical (a) and SEM images (b-c) of GaInP2/GaAs/Ge triplejunction samples with or without GaN nanostructures. Scale bar: $5 \mu \mathrm{m}$. 


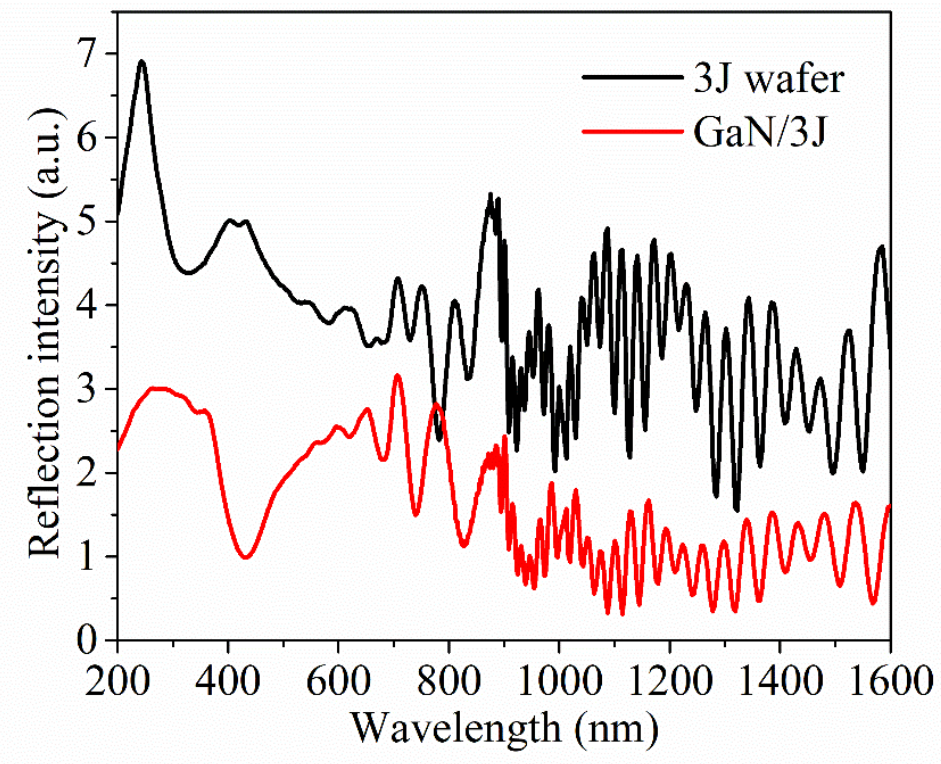

Supplementary Figure S4. Ellipsometric spectra measured for surface light reflection of $\mathrm{GaN}$ protected 3J wafer and bare 3J wafer, showing reduced reflection for GaN/3J. 

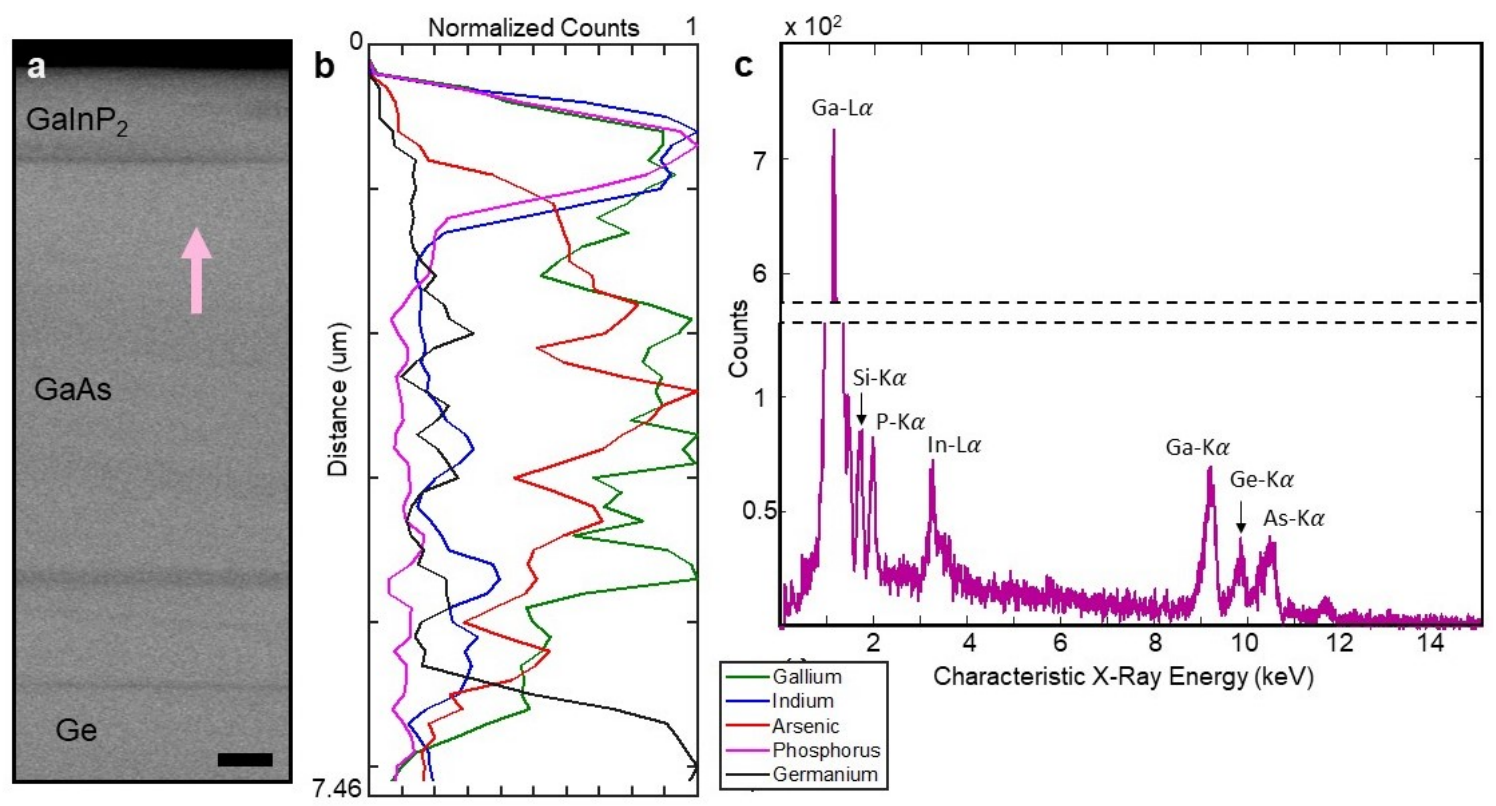

Supplementary Figure S5. (a) Side-view backscatter electron (BSE) SEM image of the GaN/3J photocathode. Scale bar: 500nm. (b) Normalized concentration of Ga, In, As, P, and Ge measured by EDX along the growth direction (indicated by the pink arrow in panel a). (c) EDX spectrum highlighting the average composition of the GaN/3J photocathode. 


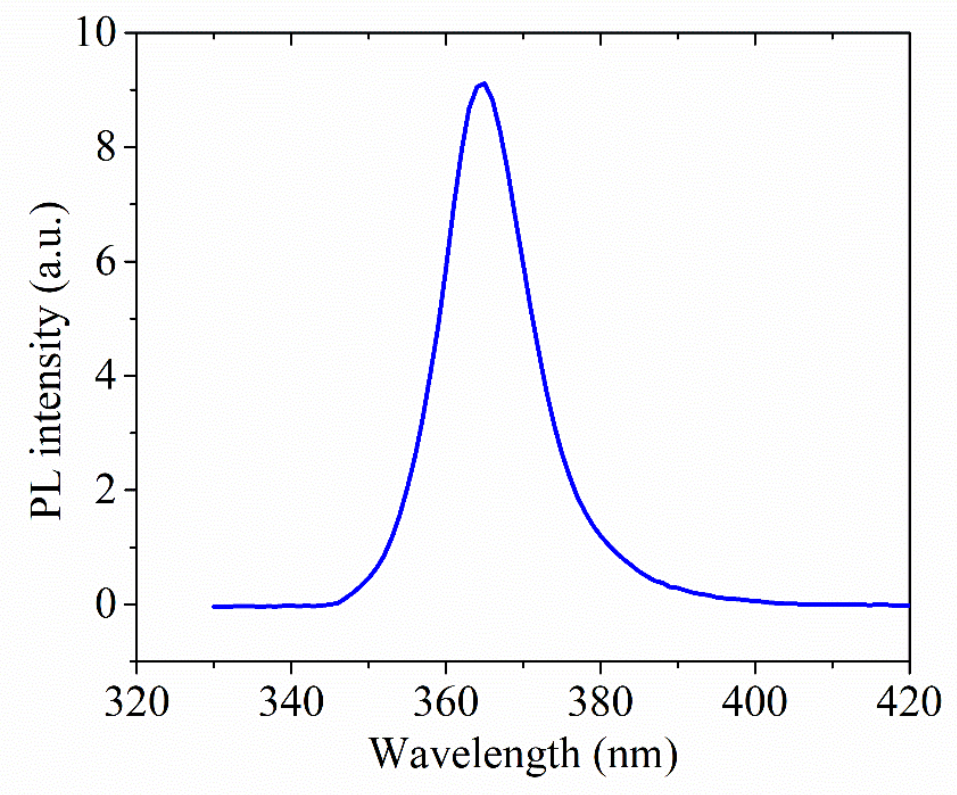

Supplementary Figure S6. Photoluminescence emission spectrum of the multifunctional $\mathrm{GaN}$ nanostructures measured at room temperature using a He-Cd $325 \mathrm{~nm}$ excitation laser. 


\section{Supplementary Note S1: Applied-bias photon-to-current conversion efficiency}

In the three-electrode configuration, applied-bias photon-to-current efficiency (ABPE) is defined to evaluate the performance for solar water half reaction, i.e., so-called water reduction reaction. For the GaN/3J photocathode shown in Figure 3, ABPE values can be calculated using Eqn. (1). ${ }^{4}$

$$
\operatorname{ABPE}(\%)=\frac{J_{p h}\left(m A \cdot c m^{-2}\right) \times V_{a p p}(V v s . R H E)}{P_{i n}\left(m W \cdot c m^{-2}\right)} \times 100 \%
$$

where $\mathrm{J}_{\mathrm{ph}}$ is the measured photocurrent of a photocathode in a three-electrode configuration (Figure 3b), $\mathrm{V}_{\text {app }}$ represents the external electric bias (V vs. RHE), and Pin is power density of the incident light (100 $\mathrm{mW} \mathrm{cm}^{-2}$ in this work). 


\section{Supplementary Note S2: Solar-to-hydrogen conversion efficiency}

For overall water splitting measured in two-electrode configuration, the solar-tohydrogen (STH) conversion efficiency is defined as the chemical energy of generated $\mathrm{H}_{2}$ gas divided by the solar energy of incident light, which can be simplified to the output power divided by incident solar power. The energy conversion efficiency for solar water splitting is measured in two-electrode configuration without any sacrificial reagents. We can calculate the STH efficiency using Eqn. (2) below, ${ }^{5}$ based on the photocurrent measurement at zero bias in Figure 4c.

$$
\mathrm{STH}=\left[\frac{J_{p h}\left(m A \mathrm{~cm}^{-2}\right) \times 1.23 V}{P_{\text {in }}\left(m W \mathrm{~cm}^{-2}\right)}\right]_{A M 1.5 G}
$$

where $\mathrm{J}_{\mathrm{ph}}$ is the measured photocurrent at zero bias in a two-electrode configuration, and Pin is power density of the incident light $\left(100 \mathrm{~mW} \mathrm{~cm}^{-2}\right.$ in this work). 


\section{Supplementary Note S3: $\mathrm{H}_{2}$ gas production by Faradaic law}

$\mathrm{H}_{2}$ gas production of $\mathrm{GaN} / 3 \mathrm{~J}$ photocathode was measured in two-electrode configuration for 2.5 hours unassisted solar water splitting using a gas chromatograph (GC-8A, Shimadzu). In addition, the ideal gas production can be calculated using Eqn. (3) below based on the Faraday's law of water electrolysis. ${ }^{6,7}$ Therefore, we can calculate the theoretical $\mathrm{H}_{2}$ gas production by assuming a unity faradaic efficiency $(\eta=1)$, shown as the solid line in Figure 4e. Due to the nearly perfect match between the measured $\mathrm{H}_{2}$ production and the calculated values, demonstrated in Figure 4e, the faradaic efficiency is estimated to be nearly unity.

$$
H_{2} \text { production }=0.5 \times \frac{\int_{0}^{t} J_{p h} d t}{F} \times \eta
$$

where $\mathrm{J}_{\mathrm{ph}}$ is the measured photocurrent during solar water splitting experiments, $\mathrm{t}$ is the experimental time for solar water splitting, F represents the Faraday constant (96485 C $\left.\mathrm{mol}^{-1}\right)$, and $\eta$ is the faradaic efficiency. 
Supplementary Table S1. Summary of stability of some previously reported highefficiency photocathodes measured in three-electrode (3E) configuration for half-cell water reduction reaction and in two-electrode (2E) configuration for unassisted solar water splitting, and the comparison with the GaN/3J photocathode presented in this work. All measurements were performed under AM 1.5G one-sun illumination.

\begin{tabular}{lcccccc}
\hline \multicolumn{1}{c}{ Materials } & $\begin{array}{c}\text { STH } \\
\text { efficiency }\end{array}$ & Electrolyte & $\begin{array}{c}\text { 3E } \\
\text { stability }\end{array}$ & $\begin{array}{c}\text { 2E } \\
\text { stability }\end{array}$ & $\begin{array}{c}\text { Surface } \\
\text { protection }\end{array}$ & Ref. \\
\hline $\begin{array}{l}\text { Platinized Multi-functional } \\
\text { GaN/3J }\end{array}$ & $12.6 \%$ & $\mathrm{H}_{2} \mathrm{SO}_{4}$ & 80 hours & 57 hours & $\mathrm{GaN}$ & This work \\
$\begin{array}{l}\text { Inverted metamorphic } \\
\text { PtRu-GaInP/GaInAs }\end{array}$ & $16.2 \%$ & $\mathrm{H}_{2} \mathrm{SO}_{4}$ & 10 hours & 1 hour & $\mathrm{TiO}_{2}$ & 8 \\
$\begin{array}{l}\text { Pt-AlInPOx/AlInP/ } \\
\text { GaInP/GaInAs }\end{array}$ & $14 \%$ & $\mathrm{HClO}_{4}$ & 16 hours & $<0.5$ & $\mathrm{Rh} \mathrm{film/}$ & 9 \\
$\begin{array}{l}\text { Ru-TiO} / \text { oxide/AlInP/GaInP/ } \\
\text { GaInAs/GaAs }\end{array}$ & $19.3 \%$ & $\mathrm{KH}_{2} \mathrm{PO}_{4} /$ & 50 hours & 1.6 hour & $\mathrm{TiO}_{2}$ & 10 \\
\hline
\end{tabular}


Supplementary Table S2. GaInP2/GaAs/Ge triple-junction (3J) structure used in this work for preparing GaN/3J photocathode.

\begin{tabular}{llllll}
\hline Layer & Materials & $\begin{array}{l}\text { Thickness } \\
(\boldsymbol{\mu m})\end{array}$ & Dopant & Doping type & $\begin{array}{l}\text { Dopant concentration } \\
\left(\mathbf{c m}^{-3}\right)\end{array}$ \\
\hline 11 & $\mathrm{Ga}_{0.44} \mathrm{In}_{0.56} \mathrm{P}$ & 0.1 & Silicon & $\mathrm{N}$ & $5 \mathrm{E}+17$ \\
10 & $\mathrm{Ga}_{0.44} \mathrm{In}_{0.56} \mathrm{P}$ & 0.5 & Zinc & $\mathrm{P}$ & $1.2 \mathrm{E}+17$ \\
9 & $\mathrm{Al}_{0.11} \mathrm{Ga}_{0.33} \mathrm{In}_{0.56} \mathrm{P}$ & 0.03 & Zinc & $\mathrm{P}$ & $1 \mathrm{E}+18$ \\
8 & $\mathrm{Al}_{0.45} \mathrm{Ga}_{0.55} \mathrm{As}$ & 0.06 & Carbon & $\mathrm{P}$ & $2 \mathrm{E}+20$ \\
7 & $\mathrm{Ga}_{0.44} \mathrm{In}_{0.56} \mathrm{P}$ & 0.06 & Tellurium & $\mathrm{N}$ & $1 \mathrm{E}+20$ \\
6 & $\mathrm{Ga}_{0.98} \mathrm{In}_{0.02} \mathrm{As}$ & 0.1 & Silicon & $\mathrm{N}$ & $5 \mathrm{E}+18$ \\
5 & $\mathrm{Ga}_{0.98} \mathrm{In}_{0.02} \mathrm{As}$ & 3.4 & Zinc & $\mathrm{P}$ & $1.2 \mathrm{E}+17$ \\
4 & $\mathrm{Ga}_{0.44} \mathrm{In}_{0.56} \mathrm{P}$ & 0.1 & Zinc & $\mathrm{P}$ & $1 \mathrm{E}+18$ \\
3 & $\mathrm{GaAs}_{2}$ & 0.08 & Carbon & $\mathrm{P}$ & $1 \mathrm{E}+20$ \\
1 & $\mathrm{GaAs}$ & 0.03 & Tellurium & $\mathrm{N}$ & $6 \mathrm{E}+19$ \\
0 & $\mathrm{Ga}_{0.98} \mathrm{In}_{0.02} \mathrm{As}$ & 0.8 & Silicon & $\mathrm{N}$ & $5 \mathrm{E}+18$ \\
\hline
\end{tabular}


Supplementary Table S3. Summary of the photoelectrochemical performance of previously reported high-efficiency photocathodes achieving unassisted solar water splitting, and the comparison with the GaN/3J photocathode presented in this work. All measurements were performed under AM 1.5G one-sun illumination unless noted.

\begin{tabular}{|c|c|c|c|c|}
\hline Materials & $\begin{array}{c}\text { STH } \\
\text { efficiency } \\
(\%)\end{array}$ & $\begin{array}{c}\text { Unbiased } \\
\text { stability } \\
\text { (hours) }\end{array}$ & $\begin{array}{c}\text { Extra } \\
\text { Protection } \\
\text { layer } \\
\end{array}$ & Year [Ref.] \\
\hline Platinized Multi-functional GaN/3J & 12.6 & 57 & $\mathrm{GaN}$ & This work \\
\hline $\begin{array}{l}\mathrm{Rh}-\mathrm{TiO}_{2} \text {-AlInP/GaInP- } \\
/ \mathrm{GaInAs} / \mathrm{GaAs}-\mathrm{RuO}_{\mathrm{x}}\end{array}$ & 19.3 & 1.6 & $\mathrm{TiO}_{2}$ & $2018[10]$ \\
\hline $\begin{array}{l}\text { PtRu-GaInP/AlInP/GaInP- } \\
\text { GaInP/GaInAs }\end{array}$ & 16.2 & 1 & n-GaInP & 2017 [8] \\
\hline $\begin{array}{l}\text { Pt-metal } / \mathrm{n}^{+} \mathrm{pGaAs} \& \\
\mathrm{IrO}_{\mathrm{x}}-\text {-metal } \mathrm{p}^{+} \mathrm{nGaAs}\end{array}$ & 13.1 & N/A & $\begin{array}{l}\text { ohmic metal } \\
\text { layer }\end{array}$ & $2017[11]$ \\
\hline Pt-TiO 2 -3J-SUS- $\mathrm{IrO}_{2}{ }^{[\mathrm{a}]}$ & 11.2 & 2 & $\mathrm{TiO}_{2}$ & 2017 [12] \\
\hline 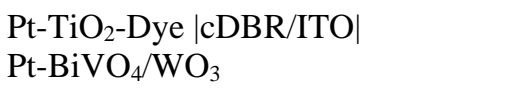 & 7.1 & 10 & $\mathrm{TiO}_{2}$ & 2016 [13] \\
\hline $\mathrm{Rh} / \mathrm{AlInP}-\mathrm{GaInP} / \mathrm{GaInAs}-\mathrm{RuO}_{2}$ & 14 & 0.04 & N/A & 2015 [9] \\
\hline $\mathrm{Pt} / \mathrm{GaInP}_{2} / \mathrm{GaAs}^{[\mathrm{b}]}$ & 12.4 & 20 & N/A & $1998[14]$ \\
\hline
\end{tabular}

[a] A wireless device.

[b] Measured under $1190 \mathrm{~mW} / \mathrm{cm}^{2}$ tungsten-halogen white light illumination. 


\section{Supplementary References}

(1) Walukiewicz, W. Intrinsic limitations to the doping of wide-gap semiconductors. Phys. B Condens. Matter 2001, 302-303, 123-134.

(2) Van de Walle, C. G.; Neugebauer, J. Universal alignment of hydrogen levels in semiconductors, insulators and solutions. Nature 2003, 423, 626.

(3) Ager, J. W.; Wu, J.; Yu, K. M.; Jones, R. E.; Li, S. X.; Walukiewicz, W.; Haller, E.

E.; Lu, H.; Schaff, W. J. In Group III-nitride alloys as photovoltaic materials, Optical Science and Technology, the SPIE 49th Annual Meeting, SPIE: 2004; p 8.

(4) Vanka, S.; Arca, E.; Cheng, S.; Sun, K.; Botton, G. A.; Teeter, G.; Mi, Z. High efficiency Si photocathode protected by multifunctional GaN nanostructures. Nano Lett. 2018, 18 (10), 6530-6537.

(5) Ager, J. W.; Shaner, M. R.; Walczak, K. A.; Sharp, I. D.; Ardo, S. Experimental demonstrations of spontaneous, solar-driven photoelectrochemical water splitting. Energy Environ. Sci. 2015, 8 (10), 2811-2824.

(6) Svengren, H.; Chamoun, M.; Grins, J.; Johnsson, M. Water splitting catalysis studied by using real-time Faradaic efficiency obtained through coupled electrolysis and mass spectrometry. ChemElectroChem 2017, 5 (1), 44-50.

(7) AlOtaibi, B.; Nguyen, H. P. T.; Zhao, S.; Kibria, M. G.; Fan, S.; Mi, Z. Highly stable photoelectrochemical water splitting and hydrogen generation using a double-band InGaN/GaN core/shell nanowire photoanode. Nano Lett. 2013, 13 (9), 4356-4361.

(8) Young, J. L.; Steiner, M. A.; Döscher, H.; France, R. M.; Turner, J. A.; Deutsch, Todd G. Direct solar-to-hydrogen conversion via inverted metamorphic multi-junction semiconductor architectures. Nat. Energy 2017, 2, 17028. 
(9) May, M. M.; Lewerenz, H.-J.; Lackner, D.; Dimroth, F.; Hannappel, T. Efficient direct solar-to-hydrogen conversion by in situ interface transformation of a tandem structure. Nat. Commun. 2015, 6, 8286.

(10) Cheng, W.-H.; Richter, M. H.; May, M. M.; Ohlmann, J.; Lackner, D.; Dimroth, F.; Hannappel, T.; Atwater, H. A.; Lewerenz, H.-J. Monolithic photoelectrochemical device for direct water splitting with 19\% efficiency. ACS Energy Lett. 2018, 3 (8), 1795-1800.

(11) Kang, D.; Young, J. L.; Lim, H.; Klein, W. E.; Chen, H.; Xi, Y.; Gai, B.; Deutsch, T. G.; Yoon, J. Printed assemblies of GaAs photoelectrodes with decoupled optical and reactive interfaces for unassisted solar water splitting. Nat. Energy 2017, 2, 17043.

(12) Okamoto, S.; Deguchi, M.; Yotsuhashi, S. Modulated III-V triple-junction solar cell wireless device for efficient water splitting. J. Phys. Chem. C 2017, 121 (3), 13931398.

(13) Shi, X.; Jeong, H.; Oh, S. J.; Ma, M.; Zhang, K.; Kwon, J.; Choi, I. T.; Choi, I. Y.; Kim, H. K.; Kim, J. K.; Park, J. H. Unassisted photoelectrochemical water splitting exceeding 7\% solar-to-hydrogen conversion efficiency using photon recycling. Nat. Commun. 2016, 7, 11943.

(14) Khaselev, O.; Turner, J. A. A monolithic photovoltaic-photoelectrochemical device for hydrogen production via water splitting. Science 1998, 280 (5362), 425. 